\title{
Retour sur « L'Outil, l'esprit et la machine »
}

\section{Tim Ingold}

\section{OpenEdition}

Journals

Édition électronique

URL : https://journals.openedition.org/tc/5197

DOI : $10.4000 /$ tc. 5197

ISSN : 1952-420X

\section{Éditeur}

Éditions de l'EHESS

\section{Édition imprimée}

Date de publication : 30 juin 2010

Pagination : 288-290

ISSN : 0248-6016

\section{Référence électronique}

Tim Ingold, « Retour sur « L'Outil, l'esprit et la machine » », Techniques \& Culture [En ligne], 54-55 | 2010, mis en ligne le 30 janvier 2013, consulté le 29 septembre 2022. URL : http://journals.openedition.org/ tc/5197; DOl : https://doi.org/10.4000/tc.5197 


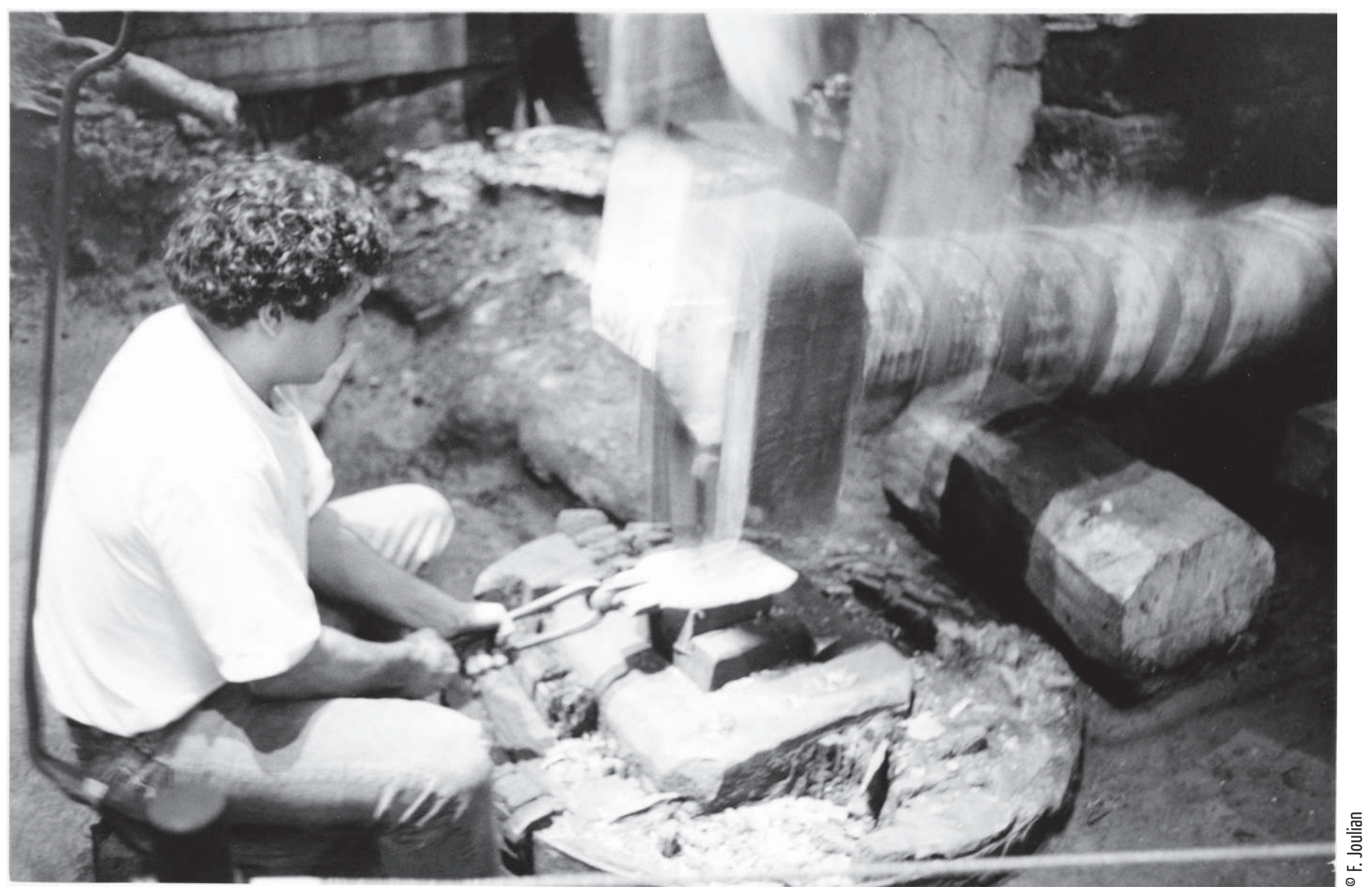


Tim Ingold

University of Aberdeen

tim.ingold@abdn.ac.uk
Cultures matérielles 1 - IV

Techniques \& Culture 54-55 volume 1, 2010 : 288-290

\section{Retour sur}

\section{« L'Outil, l'esprit et la machine»}

Dans les sociétés occidentales nous avons tendance à penser l'art et la technique comme des champs d'action séparés. L'étude de chacun d'eux s'est constituée sur des fondations distinctes. Dans cet article, comme dans d'autres qui lui feront suite (Ingold 2000, 2001, 2002), j’ai tenté de montrer comment dépasser cette séparation entre art et technique en prenant comme point de départ les savoir-faire et les agents sociaux, en situation, et plus largement de repenser « le technique ».

En commençant à travailler sur cet article, il m'est apparu que l'opposition entre conception intellectuelle et exécution machinique - dans les termes dans lesquels se pose habituellement le débat de la fabrication et de l'utilisation d'outils chez les hommes et les animaux -, est en fait un phénomène lié à la modernité occidentale. Au lieu d'assumer que les opérations techniques sont de nature mécanique, j'avance l'idée que la machine est un aboutissement du développement historique des forces de production accompagnant l'expansion du capitalisme industriel. Au cours de ce développement, les relations entre les travailleurs, les outils et la matière première ont été modifiées, - comme dans le remplacement des habiletés portées par le sujet -, par les principes objectifs du fonctionnement mécanique. C'est à ces principes que le concept moderne de technologie renvoie. Je montrais dans cet article comment l'émergence de ce concept était liée au développement d'une cosmologie mécanicienne qui sépare le design (la conception) de la réalisation et réduit le savoir-faire à une «simple exécution technique ». Ainsi, alors que dans le maniement des outils par l'artisan les mouvements sont guidés par sa propre perception, les mouvements de la machine, ou de n'importe quel outil qui lui est fixée, sont à l'inverse, prédéterminés. Je concluais que, dans l'histoire de la technicité humaine qui va de l'outil manuel à la machine, la transition ne va pas du simple au compliqué mais est plutôt équivalente au déplacement du producteur, en tant que personne, du centre vers la périphérie 
du processus de production. En d'autres termes, c'est une histoire, une externalisation et non une complexification à laquelle nous avons affaire. D'autres articles suivront tant sur l'importance des savoir-faire et des capacités à percevoir ou mettre en actes chez les chasseurs-cueilleurs qu'à celle des déterminismes de l'environnement ou de la matière qui doivent être remplacés par des chaînes de causalités bien plus complexes, impliquant les dimensions corporelles, sociales ou politiques.

Dans des travaux ultérieurs je suis revenu sur la dichotomie moderne entre art et technique, qui empêche, selon moi, d'apprécier la véritable nature de l'habileté technique (Ingold 2001). Pour définir plus précisément ce que j'entends par habileté je souligne cinq dimensions discriminantes de toute pratique habile. Premièrement, viennent l'intentionnalité et la fonctionnalité qui plutôt que d'être des propriétés préexistantes d'un agent ou d'un instrument sont intimement liées à la pratique proprement dite. Deuxièmement, l'habileté n'est pas un attribut du corps isolé d'un individu, mais partie intégrante d'un système de relations matérialisé par la présence de l'artisan dans son environnement. Troisièmement, plutôt que d'être l'expression d'une simple application d'une force mécanique, l'habileté implique des qualités de soin, de jugement et de dextérité. Quatrièmement, ce n'est pas à travers la transmission de formules que les habiletés passent d'une génération à une autre mais par la pratique et l'expérience, « les mains dedans ». Finalement, le savoirfaire n'est pas là pour réaliser un dessein préexistant mais plus précisément pour générer les formes des artefacts.

Dans un article plus récent (Ingold 2006) je montre que l'utilisation experte d'un outil est analogue à une marche, dans le sens où elle s'appuie sur un cheminement à la différence de la « machinofacture » où il s'agit de relier des points déjà prédéfinis. C'est, dans ce sens, un processus ou un itinéraire, rythmique plutôt que métronomique, donné dans le couplage étroit de la perception et de l'action et dans la synergie de l'outil, du geste et de la matière. Tout au long de l'histoire du monde occidental, la technique a toutefois eu le projet de saisir les savoir-faire des acteurs et de reconfigurer leurs pratiques comme applications de principes rationnels dont les caractéristiques n'ont pas de rapports avec l'expérience ou la sensibilité humaine. Cela a eu pour résultat que la connaissance sensible et tactile de la ligne et de la surface qui avait guidé les praticiens à travers leurs matériaux variés et hétérogènes, comme les voyageurs sur le terrain, a progressivement laissé place à une architectonique de formes pures, conçue antérieurement à sa réalisation dans un médium matériel maintenant homogénéisé. Incarnée à présent dans le concept même de «technique " (Ingold 2010) se trouve une affirmation ontologique selon laquelle les choses sont constituées dans la transposition rationnelle et réglée d'une forme préconçue sur la matière inerte, plutôt que dans le tissage de - et au travers de - matériaux actifs. La technique est en résumé la réponse de la modernité à la question: " qu'est-ce que cela signifie de fabriquer des choses? »

«Le retour sur » a été traduit et adapté de la présentation faite par l'auteur de son texte dans la III ${ }^{e}$ partie de « The perception of the environment: essays on livelihood, dwelling and skill », Ingold, T. 2000. 